\title{
Determination of structure and morphology of the cyclodextrins-iodine complexes
}

\section{Maksym Polumbryk ${ }^{1}$, Vasyl Pasichnyi ${ }^{1}$, Chrystyna Omelchenko ${ }^{1}$, Oleksii Vyshnevskiy ${ }^{2}$}

\author{
1 - National university of food technologies, Kyiv, Ukraine \\ 2 - M.P. Semenenko Institute of geochemistry, mineralogy and ore formation of the \\ National Academy of sciences of Ukraine
}

\section{Keywords: \\ Scanning electric microscopy \\ Surface morphology \\ Cyclodextrin \\ Iodine \\ Inclusion complex}

\section{Article history:}

Received

24.11.2016

Received in revised form 27.02.2017

Accepted 30.03.2017

\section{Corresponding author:}

Maksym Polumbryk E-mail:

mx_pol@yahoo.com

DOI:

10.24263/2304-

974X-2017-6-1-13

\section{Abstract}

Introduction. The objective of these investigations is to study surface morphology of inclusion complexes between $\alpha$ - and $\beta$ cyclodextrins and molecular iodine as well as determine chemical stoichiometric ratio between these components in the formed complexes.

Materials and methods. The host-guest complexes between $\alpha$ and $\beta$-cyclodextrins and iodine were synthesized according to the procedures, given in literature sources.. Morphology of the surface of the samples has investigated by use of scanning electronic microscope JSM-6700F (JEOL, Japan). The platinum layer with $10 \mathrm{~nm}$ in depth was preliminary placed on the samples. The samples were mounted on SEM and irradiated with beam of electrons at $15 \mathrm{kV}$ and probe current $0,65 \mathrm{nA}$.

Results and discussion. The scanning electronic microscopy (SEM) has been used in order to investigate morphology and structural features of the obtained complexes. This method has widely used in macromolecules analysis. It allows precise determination of elemental content in the samples. The results of iodine content in inclusion compounds with $\alpha$ - and $\beta$-cyclodextrins obtained from SEM and iodimetrical titration methods are almost similar. It has found, that iodine content in $\beta-C D-\mathrm{I}_{2}$ complex within the range $16,7-16,9 \%$, whereas $\alpha-\mathrm{CD}-\mathrm{I}_{2}$ consisted $18,0-19,9 \%$ of active iodine. Some differences were found in respect to the iodine content in $\alpha-\mathrm{CD}-\mathrm{I}_{2}$, obtained by two methods may related to the high water absorption on the complex surface result in the drop of iodine content on the surface. Experimental data of iodine content in the inclusion complexes suggested that $\alpha$ - and $\beta$-cyclodextrins react with $\mathrm{KI}_{3}$ resulted in the host guest complex formation with the chemical stoichiometric ratio value of $1: 1$. Analysis of surface morphology of the cyclodextrin-iodine samples obtained from high resolution SEM method revealed about coarse crystalline structures formation, which is nontypical for organic polymeric compounds. Comparative studies have revealed, that cyclodextrin: iodine ratio in the obtained complexes is $1: 1$. It has been confirmed that one molecule of cyclodextrin bound one molecule of iodine, forming host-guest complex.

Conclusions. The complex $\beta$-cyclodextrin- $I_{2}$ was loss $9 \%$ of active iodine at the prolonged storage during 1 year at $4{ }^{\circ} \mathrm{C}$. It was shown, that iodine content in the $\alpha-\mathrm{CD}-\mathrm{I}_{2}$ and $\beta-\mathrm{CD}-\mathrm{I}_{2}$ can be estimated with use of relatively simple and quick method of iodimetric titration, which is being important property of these complexes for their further application in food technologies. 


\section{Introduction}

Cyclodextrins (CDs) are the cyclic oligosaccharides, composed from residues of $\alpha-\mathrm{D}-$ glucopyranoses, made during starch transformation by specific enzymes, for example Bacillus macerans. Cyclodextrins belonging to ring molecules, which due to rigid glycosidic bonds between glucopyranose units have a toroidal form. The most widely used CDs are so called $\alpha-, \beta$ - and $\gamma$-cyclodextrin, which consisted six, seven and eight glucose units, respectively. Unique properties of cyclodextrins related to their ability of inclusion complexes formation in which non-polar guest molecule substitute water molecules from internal cavity of the host molecule which is leading to the complex formation $[1,2]$. The most common chemical stoichiometric ratio between cyclodextrins and guest molecules is $1: 1[1,3]$.

These complexes have been widely used in food technologies, particularly in oilsoluble compounds protection sensible to the oxygen, light and high temperatures action as well as improvement of vitamins solubility; taste and aroma stabilization of essential oils, undesirable compounds removal, lipophilic compounds solubilization, as photostabilization of light sensitive compounds, catalytic activity retention, protection from enzymatic deterioration, unnecessary taste and aroma suppression, controlled release of some food components e.t.c. CDs themselves can be recognized as non-digestible oligosaccharides and, thus, their consumption can improve beneficial microflora in gastrointestinal tract.

We have earlier synthesized host-guest complex between $\beta$-cyclodextrin and molecular iodine and applied this compounds as a food additive in boiled sausages formulation $[4,5]$. This compound can be considered as a promising iodophor, which able to increase iodine status of humans. According with experimental data, regular consumption of these boiled sausages by adult individuals resulted in significant improvement of their iodine status. The sensory and microbiological characteristics of the boiled sausages made with $\mathrm{CD}-\mathrm{I}_{2}$ inclusion and standard samples were similar so that this complex has no negative impact on quality of the boiled sausages $[4,6]$.

$\mathrm{X}$-ray analysis suggests that iodine and cyclodextrins form linear polymer chain in which one molecule of $\mathrm{CD}$ can bind more than one iodine molecule [7]. At the same time, however, other authors indicated that $\mathrm{CD}$ and iodine react with the complex formation, in which one molecule of $\beta$-cyclodextrin quench one molecule of iodine [8]. This inconsistency in iodine content of CD-iodine complexes is substantial obstacle that complicates wide application of CD-iodine complexes in food technologies and confuses rapid iodine determination

The objective of these investigations is to study surface morphology of inclusion complexes between $\alpha$ - and $\beta$-cyclodextrins and molecular iodine as well as determine chemical stoichiometric ratio between these components in the formed complexes.

\section{Materials and methods}

\section{Materials}

$\mathrm{I}_{2}, \alpha$ - and $\beta$-cyclodextrin, DMF, KI were offered from Sigma-Aldrich. Unless specific notifications, all the chemicals were analytical reagent grade without further purification. 
Synthesis of $\beta$-cyclodextrin- $I_{2}$ complex.

Synthesis of $\beta-C D / I_{2}$ complex was done according to synthesis procedure, described by Wang and co-authors [8]. $3,8 \mathrm{~g}$ of $\mathrm{KI}$ and $0,38 \mathrm{~g}$ of $\mathrm{I}_{2}(1,5 \mathrm{mM})$ were dissolved in $15 \mathrm{ml}$ of distilled water during 10 minutes resulted in $\mathrm{KI}_{3}$ formation. Further, this solution was dropped into $10 \mathrm{ml} \beta$-cyclodextrin solution $(223 \mathrm{mg}, 0,5 \mathrm{mM})$ in $50 \mathrm{ml}$ conical flask. The mixture was stirred during $5 \mathrm{~h}$ at $25{ }^{\circ} \mathrm{C}$ and then retained $10 \mathrm{~h}$ at $4{ }^{\circ} \mathrm{C}$ in order to fully encapsulate iodine in $\beta$-CD. After storage, brown crystals of $\beta-\mathrm{CD} / \mathrm{I}_{2}$ were filtered and washed KI solution in order to remove $\mathrm{I}_{2}$ molecules from the filter cake and distilled water which aid to get rid from both $\mathrm{KI}$ and $\beta$-CD. The final product was dried at vacuum during $4 \mathrm{~h}$ at $40{ }^{\circ} \mathrm{C}$. The total preparative yield was $93 \%$.

Iodine content in the complex was determined by iodimetrical titration, described by Wang and co-authors [8]. Sample of $\alpha-$ or $\beta-\mathrm{CD} / \mathrm{I}_{2}(0,2 \mathrm{~g})$ was weighed precisely, when placed in the $10 \mathrm{ml}$ flask and $4 \mathrm{ml}$ of DMF was added and stirred until complete dissolution. When $140 \mathrm{ml}$ of deionized water was added and titred by $\mathrm{Na}_{2} \mathrm{~S}_{2} \mathrm{O}_{3}$ standard solution $(0,01 \mathrm{M})$. Titration was continued until the solution turned out light yellow and added $3 \mathrm{ml}$ starch-iodine indicator and keep on titrating until solution became colorless. Titration procedure was repeated thrice. The iodine content was calculated by formula:

$\mathrm{I}(\%)=0,1269 \times \mathrm{C}\left(\mathrm{Na}_{2} \mathrm{~S}_{2} \mathrm{O}_{3}\right) \times \mathrm{V}\left(\mathrm{Na}_{2} \mathrm{~S}_{2} \mathrm{O}_{3}\right) \times 100 / \mathrm{m}$

The iodine content in the complex was $16,9 \pm 0,1 \%$, which corresponds equimolecular ratio of $\beta-C D$ and $I_{2}$ in the complex. Moreover, we determined melting point of $\beta-C D / I_{2}$ in capillary tube, which was $76^{\circ} \mathrm{C}$. This value is in agreement with the data obtained by Wang and co-auth [8].

$\alpha-\mathrm{CD} / \mathrm{I}_{2}$ complex has synthesized by the same manner, taking to account that $\alpha$ cyclodextrin more soluble in aqueous solution than $\beta-\mathrm{CD}$. The total preparative yield was $94,5 \%$.

\section{Methods}

The scanning electronic microscopy (SEM) has been used in order to investigate morphology and structural features of the obtained complexes. This method has widely used in determination of macromolecules analysis. It allows precise determination of elemental content in the samples [9].

Morphology of the surface of the samples has investigated by use of scanning electronic microscope JSM-6700F (JEOL, Japan). The samples were applied on metal slab, and preliminary were coated with platinum layer with $10 \mathrm{~nm}$ in dept. The samples were mounted on SEM and irradiated with beam of electrons at $15 \mathrm{kV}$ and probe current 0,65 nA.

\section{Results and discussion}

The experimental data of iodine content in the complexes, obtained by several methods was given in the table 1 . According with these data molecular iodine is interacting with $\alpha$ or $\beta$-CD resulted in the host-guest complex formation with the ratiol:1.

These results are not agreed with the known X-ray diffraction assays, which indicates, that $\beta$-cyclodextrin form with iodine inclusion complex $\beta-\mathrm{CD}-\mathrm{I}_{7}^{-}$, whereas interaction between $\alpha$-cyclodextrin and iodine resulted with complex formation with total formula $\alpha$ CD- $\mathrm{I}_{5}{ }^{-}[6]$. The authors suggested that polyiodide chain consists of discrete $\mathrm{I}_{7}{ }^{-}$units, which can be formulated as $\mathrm{I}_{2} \cdot \mathrm{I}_{3}{ }^{-} \cdot \mathrm{I}_{2}$. These units are shaped into Z-like structures. Furthermore, in 
the $\alpha-\mathrm{CD}_{-} \mathrm{I}_{5}{ }^{-}$complex, $\alpha-\mathrm{CD}$ molecules are stacked together to form columns similar to nanotubes, and $\mathrm{I}_{5}{ }^{-}$ions are located in the columns and nearly linerly arranged in the direction of columns [10].

Iodine content (\%) in cyclodextrin-iodine complexes

Table 1

\begin{tabular}{|c|c|c|}
\hline Complex & SEM & Titration \\
\hline$\alpha-\mathrm{CD}^{-} \mathrm{I}_{2}$ & $18,0 \pm 0,2$ & $19,9 \pm 0,1$ \\
\hline$\beta-\mathrm{CD} \mathrm{I}_{2}$ & $16,82 \pm 0,4$ & $16,9 \pm 0,1$ \\
\hline$\beta-\mathrm{CD}-\mathrm{I}_{2}(1$ year storage) & $15,42 \pm 0,3$ & $14,9 \pm 0,1$ \\
\hline
\end{tabular}

As it can be seen from the table 1, the results of iodine content in inclusion compounds with $\alpha$ - and $\beta$-cyclodextrins obtained from SEM and iodimetrical titration methods are almost similar. These evidences indicates both high reproducibility of complexes synthesis procedure and precision of iodimetric titration method. However, some differences are found in respect to the iodine content in $\alpha-C D-I_{2}$, obtained by two methods may related to the high water absorption on the complex surface result in the drop of iodine content on the surface. Surprisingly, the data of iodine content in the samples obtained from iodimetric titration is close to the theoretically estimated on the basis of individual atomic weight. Thus, experimental data of iodine content in the inclusion complexes suggested that $\alpha$ - and $\beta$-cyclodextrins react with $\mathrm{KI}_{3}$ resulted in the host guest complex formation with the chemical stoichiometric ratio value of $1: 1$. Interesting, that storage for 1 year at $4{ }^{\circ} \mathrm{C}$, indicates that $\beta-\mathrm{CD}-\mathrm{I}_{2}$ inclusion complex has lost a small amount of iodine, which can be simply and accurately determined by iodimetric titration method (Table 1). Thus, the complex has remained relatively stable during prolonged storage.

Oxygen content (\%) in cyclodextrin-iodine complexes

Table 2

\begin{tabular}{|c|c|c|}
\hline Complex & Experimental & Theoretical \\
\hline$\alpha-C D-I_{2}$ & $30,9 \pm 0,5$ & 36,3 \\
\hline$\beta-C D-I_{2}$ & $39,52 \pm 0,6$ & 38,1 \\
\hline$\beta-C D-I_{2}$ (1 year storage) & $38,7 \pm 0,5$ & 38,1 \\
\hline
\end{tabular}

The oxygen content in the samples of CDs and their complexes with iodine was derived with the help of SEM method. As it can be seen from the table 2, these data close to those theoretically calculated taking to account masses of the individual atoms constituting the bonds in the molecules (table 2). It is known, that SEM method usually is not able to give reliable data for mass content of atoms with relatively low atomic weight, like oxygen or carbon. This was observed for the carbon content in the samples, whereas SEM method provides good result for oxygen content in the samples. These findings are also indicated 
that iodine with the $\alpha$ - or $\beta$-CD will form 1:1 complex. Potassium is also present in the complexes, mainly due to KI application at the complexes synthesis. The potassium content in the samples varies within the range $0,8-1,48 \%$ which is also confirmed stoichiometric ratio of the complexes.
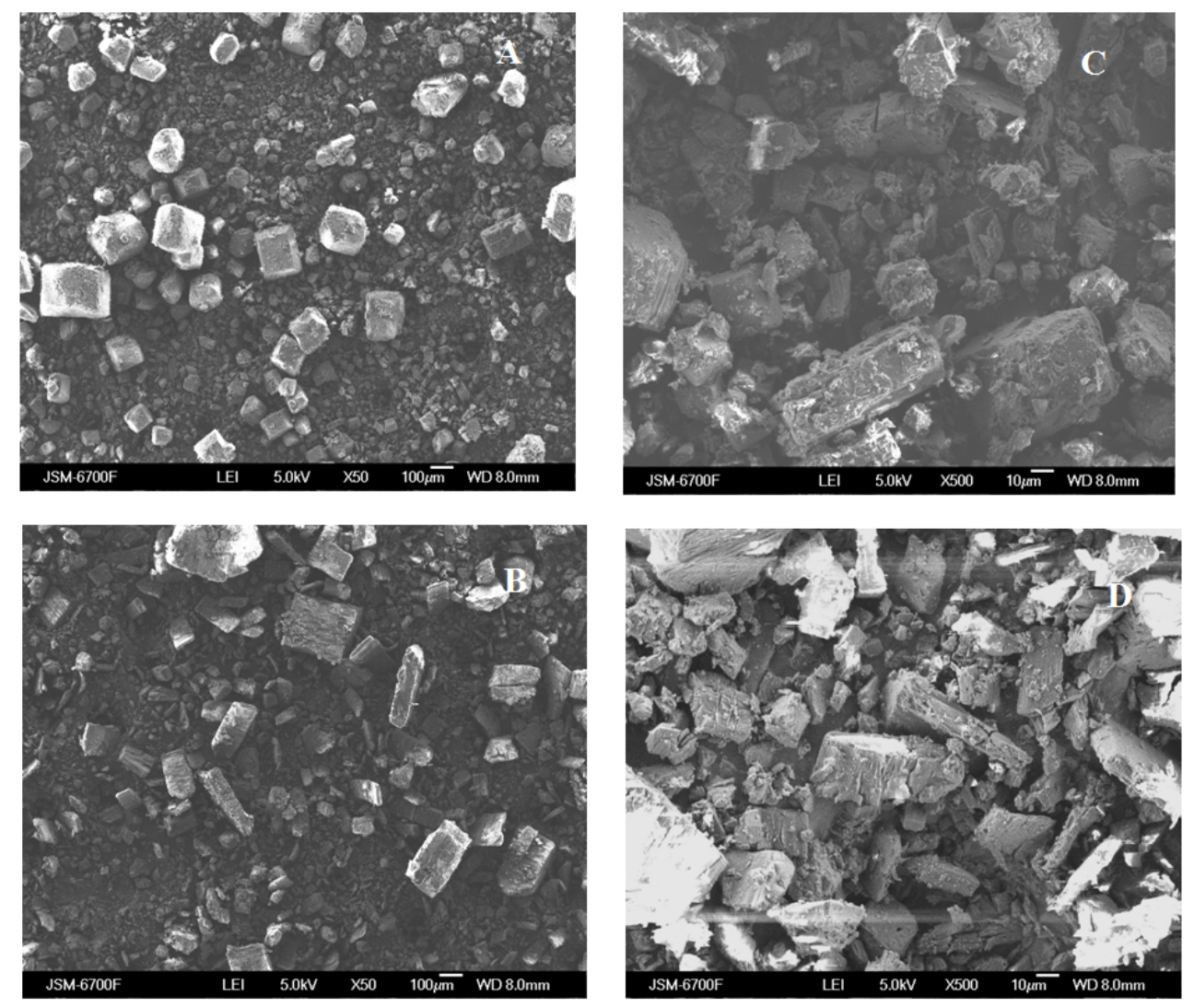

Figure 1. Scanning electronic microphotographs of the surfaces of $\alpha-C D(A)$ and $\beta-C D(B) ~ L e f t$, $50 \times$ magnification; $\alpha-C D(C)$ and $\beta-C D(D)$ Right, $500 \times$ magnification

The changes in particle morphology that occurred during CDs synthesis are indicated in the SEM study. The SEM microphotographs of $\alpha$ - and $\beta$-CD shown in Figure 1. These images observation indicates the presence of some not fully transformed starch granules in a very small amount. It is confirmed high level of starch transformation into CDs. As illustrated in Figure2, CDs complexes with iodine existed in needle like crystals, whereas $\alpha$ - and $\beta$-CD was observed as irregular "shrinked" crystals. 

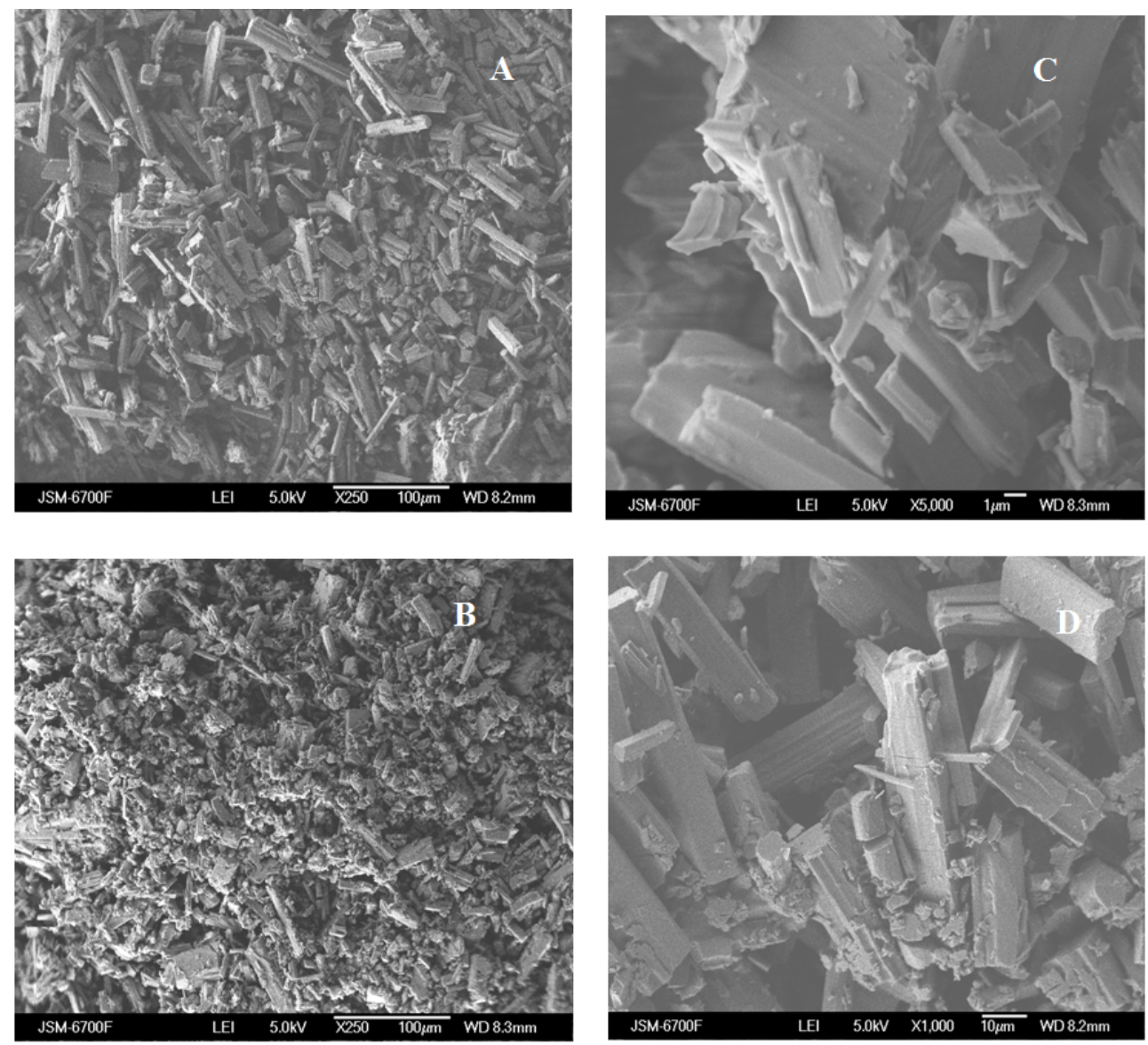

Figure 2. Scanning electronic microphotographs of the surfaces of $\alpha-C D-I_{2}(A)$ and $\beta-C D-I_{2}(B)$

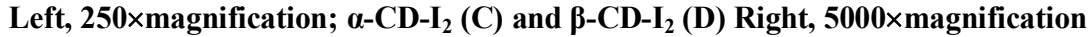

The changes in particle morphology that occurred during CDs synthesis are indicated in the SEM study (Figures 1 and 2). The SEM microphotographs of $\alpha$ - and $\beta$-CD complexes with iodine are almost similar as shown in Figure 2. It is appeared, that during synthesis, original morphology of CDs almost fully disappeared and needle shaped crystals with regular size were present.

The SEM microphotographs of CDs are similar to those obtained by Ikotun and coauth [11]. Analysis of surface morphology of the cyclodextrin-iodine samples obtained from high resolution SEM method revealed about coarse crystalline structures formation, which is nontypical for organic polymeric compounds.

The mentioned above disparity between literature data and our experimental results related to the iodine content in $\mathrm{CD}-\mathrm{I}_{2}$ inclusion complexes can be explained by intense washing of synthesized crystals by KI aqueous solution. This is obviously resulted in polyiodide chain disruption and incapsulated extrinsic molecular iodine washing out. In the 
other words, one molecule of $\alpha$ - or $\beta$-CD was binding a one molecule of iodine during synthesis.

Probably, at the initial stage of complex formation, iodine molecule bind to the molecule of cyclodextrin give rise to inclusion complex formation with stoichiometric ratio 1:1. Further, additional complexation may occur as a result of iodine interaction with the $1: 1$ complex.

\title{
Conclusions
}

Thus, comparative studies have revealed, that cyclodextrin: iodine ratio in the obtained complexes is 1:1. Reproducibility of procedure of $\mathrm{CD}-\mathrm{I}_{2}$ synthesis has confirmed. These complexes remain stable during storage for 1 year and lost approximately only $9 \%$ of iodine. It has shown, that iodine content in the $\alpha-\mathrm{CD}-\mathrm{I}_{2}$ and $\beta-\mathrm{CD}-\mathrm{I}_{2}$ can be estimated with use of relatively simple and quick method of iodimetric titration, which is being important property of these complexes for their further application in food technologies.

\begin{abstract}
Acknowledgements
The work was supported by the Ministry of Education and Science (State Project «Scientific basis for establishing of resource-saving technologies of protein containing concentrates of food products for special purposes»,, №0117U001243), Ukraine.
\end{abstract}

\section{References}

1. Polumbryk M.O., Litvyak V.V., Lovkis Z.V., Kovbasa V.N. (2016), Carbohydrates in food products, Ministry of finance publishing, Minsk.

2. Astray G., Gonzalez-Barreiro C., Mejuto J.C. et. al. (2009), A review on the use of cyclodextrins in foods, Food Hydrocolloids, 23 (7), pp. 1631-1640.

3. Song L.X., Bai L., Xu X.M. et.al.(2009), Inclusion complexation, encapsulation interaction and inclusion number in cyclodextrin chemistry, Coordination Chemistry Reviws, 253 (9-10), pp. 1276-1284.

4. Polumbryk M.O., Kotlyar Y.O., Omelchenko Ch.V., Polumbryk M.M., Pasichniy V.M. (2016), Application of the complex between $\beta$-cyclodextrin and iodine with the boiled sausages manufacturing, Food Science and technology, 10 (3), pp. 44-48.

5. Omelchenko Ch., Polumbryk M., Kirkova M., Polumbryk M. (2014), Food products fortification by essential trace elements and human life safety: a review, Ukrainian Journal of Food Science, 2(1), pp. 77-81

6. Ukrainets A.I., Pasichniy V., Zheludenko Yu.,. Zadkova S. (2016), Oleoresins effect on cooked poultry sausages microbiological stability, Ukrainian Food Journal, 5(1), pp. 124-134.

7. McMullan R.K., Saenger W., Fayoz J. et. al. (1973), Topography of cyclodextrin inclusion complexes: Part II. The iodine-cyclohexa-amylose tetrahydrate complex; its molecular geometry and cage-type crystal structure, Carbohydrate Research, 31(2), pp. 211-227. 
8. Wang T., Li B., Feng Y. et.al. (2011), Preparation, quantitative analysis and bacteriostasis of solid state iodine inclusion complex with $\beta$-cyclodextrin, Journal of Inclusion Phenomena and Macrocyclic Chemistry, 69 (2), pp. 255-262.

9. Faughey G.J., Sharma S.S., McCall R.D. (2000), Determining fiber fineness in flax using derivative thermogravimetric analysis, scanning electron microscopy, and airflow methods, Journal of Applied Polymer Science, 75 (4), pp. 508-514.

10. Noltemeyer M., Saenger W. (1980) Topography of cyclodextrin inclusion complexes. 12. Structural chemistry of linear alpha-cyclodextrin-polyiodide complexes. X-ray crystal structures of (alpha.-cyclodextrin) $)_{2} \cdot \mathrm{LiI}_{3} \cdot \mathrm{I}_{2} \cdot 8 \mathrm{H}_{2} \mathrm{O}$ and (alphacyclodextrin $)_{2} \cdot \mathrm{Cd}_{0.5}$ ). $\mathrm{I}_{5} .27 \mathrm{H}_{2} \mathrm{O}$. Models for the blue amylose-iodine complex, Journal of American Chemical Society, 102 (8), pp. 2710-2722.

11. Ikotun B.D., Mishra S., Fanourakis G.S. (2014), Study on the synthesis, morphology and structural analysis of fly ash-cyclodextrin composite, Journal of Inclusion Phenomena and Macrocyclic Chemistry, 79 (3), pp. 311-317. 